\title{
Development of an online hub for OSC outreach efforts
}

Emily Finan, Hillary Mathis, Amee Hennig, Mike Nofziger

Emily Finan, Hillary Mathis, Amee Hennig, Mike Nofziger, "Development of an online hub for OSC outreach efforts," Proc. SPIE 10741, Optics Education and Outreach V, 107410Y (14 September 2018); doi: 10.1117/12.2322089

SPIE Event: SPIE Optical Engineering + Applications, 2018, San Diego, California, United States 


\title{
Development of an online hub for OSC outreach efforts
}

\author{
Emily Finan*a ${ }^{*}$ Hillary Mathis ${ }^{\mathrm{a}}$, Amee Hennig $^{\mathrm{a}}$, Mike Nofziger ${ }^{\mathrm{a}}$ \\ ${ }^{a}$ College of Optical Sciences, The University of Arizona, 1630 E. University Blvd., Tucson, AZ, \\ USA 85721
}

\begin{abstract}
This UA/NASA Space Grant project centralizes the outreach efforts for College of Optical Science students using a new online hub, developed to collect, organize, and disseminate educational activities. Optical Sciences plays a role in many of the innovative technologies transforming our society, making outreach of utmost importance to attract students to the emerging field. Outreach activities at the University of Arizona's College of Optical Sciences (OSC) help inspire these future innovators. This website provides on-demand training for students unfamiliar with leading demonstrations and inspiration for experienced instructors looking for something new. It emphasizes scientific literacy, effective scientific communication, and serves as a free and accessible resource for STEM classrooms.

The online hub offers students new to outreach an opportunity to familiarize themselves with resources before performing outreach. Although OSC offers a semester-long outreach course that provides face-to-face training, it has the burden of class time and tuition for students. The online hub is freely available, easily accessible, and self-directed by the user's interests. Multimedia lesson plans provide instructions for effectively presenting to students and document materials required for each activity. Clear objectives are provided to guide the instruction and evaluate the students' knowledge and interest in optics. Ongoing outreach events are utilized during the academic year to "beta-test" the website. While an online hub greatly enhances the many outreach activities already available to students within the College of Optical Sciences, an online resource has the added benefit of being an accessible resource to teachers, students, and communities around the world.
\end{abstract}

Keywords: Optics education, outreach, lesson plans, training, demonstrations

\section{INTRODUCTION}

Optical Sciences plays a role in many of the innovative technologies transforming our society, making outreach of utmost importance to attract students to the emerging field. Outreach activities at the University of Arizona's College of Optical Sciences (OSC) help inspire these future innovators. This project centralizes the outreach efforts for the College of Optical Sciences using a new online hub, developed to collect, organize, and disseminate educational activities. The website provides on-demand training for students unfamiliar with leading demonstrations and inspiration for experienced instructors looking for something new. It emphasizes scientific literacy, effective scientific communication, and serves as a free and accessible multimedia resource for STEM classrooms.

\subsection{Motivation}

For decades, the College of Optical Sciences has developed an extensive collection of outreach programs led by undergraduate and graduate students, faculty, and staff ${ }^{1,2,3}$. The College of Optical Sciences contains several different organizations which participate in outreach activities within the Tucson community: Student Optics Chapter (SOCk), Women in Optics (WiO), and the Center for Integrated Access Networks (CIAN). The largest event hosted by the groups within OSC is Laser Fun Day, an annual event which attracts up to 1,000 visitors each year ${ }^{4,5}$. Additional events include classroom visits to elementary, middle, and high schools and community events such as the Tucson Festival of Books and the Southern Arizona Research, Science and Engineering (SARSEF) Future Innovator's Night. There are currently over 30 different activities available for outreach events, which continue to grow and evolve over time.

For students new to outreach, volunteering for these outreach events may be daunting. OSC does offer an Optics Outreach course (OPTI 489/589) to provide face-to-face training for performing various demonstrations for undergraduates and graduate students, but this has the burden of class time and tuition. The development of an online hub offers students new

*efinan@optics.arizona.edu; https:/wp.optics.arizona.edu/oscoutreach

Optics Education and Outreach V, edited by G. Groot Gregory, Proc. of SPIE Vol. 10741, 107410Y

(C) 2018 SPIE · CCC code: $0277-786 \mathrm{X} / 18 / \$ 18 \cdot$ doi: $10.1117 / 12.2322089$ 
to outreach an opportunity to familiarize themselves with resources before performing outreach, thereby lowering the barrier-to-entry for volunteering to lead outreach activities.

\section{METHODS}

Prior work has shown that scientists' perception of engaging in outreach activities can be affected by a variety of factors, with one of the most significant barriers being perceived time contraints ${ }^{6}$. This perception can be exacerbated when information on outreach options is not easily accessible, placing the burden of creating new opportunities on the scientist. This time and effort can discourage volunteers, particularly those new to leading demonstrations. By documenting materials available within OSC with an online repository of lesson plans and publicizing upcoming events, we hope to address this perception and encourage more members of the optics community to participate in outreach.

The development of this online resource was jumpstarted by a UA Graduate Fellowship award co-sponsored by the College of Optical Sciences and the UA/NASA Space Grant Program, which supports educational outreach projects designed to promote the understanding of space-related research to the public within the topics of space sciences or engineering, public policy, earth sciences, science education, and global change-related fields ${ }^{7}$.

\subsection{Online Hub Structure}

The online hub is freely available, easily accessible, and self-directed by the user's interests. Multimedia lesson plans provide instructions for effectively presenting to students and document materials required for each activity. Clear objectives are provided to guide the instruction and evaluate the students' knowledge and growth in interest in a particular optics concept.

The demonstrations are grouped into various categories by topic, such as fiber optics, everyday optics, electromagnetic spectrum, physical optics, and optical illusions. Lesson plans are created with the intention of appealing to all age ranges, with additional information provided for more advanced discussions.

To help coordinate between organizations within OSC, additional joint resources on the online hub include a calendar of events, comment section for each lesson plan, and a submission form to compile new demonstration ideas. Comments and submissions are moderated before being posted online. The pages are built within the same WordPress template used for websites for faculty, research groups, labs, and clubs of OSC and are moderated by the college's media content manager. 


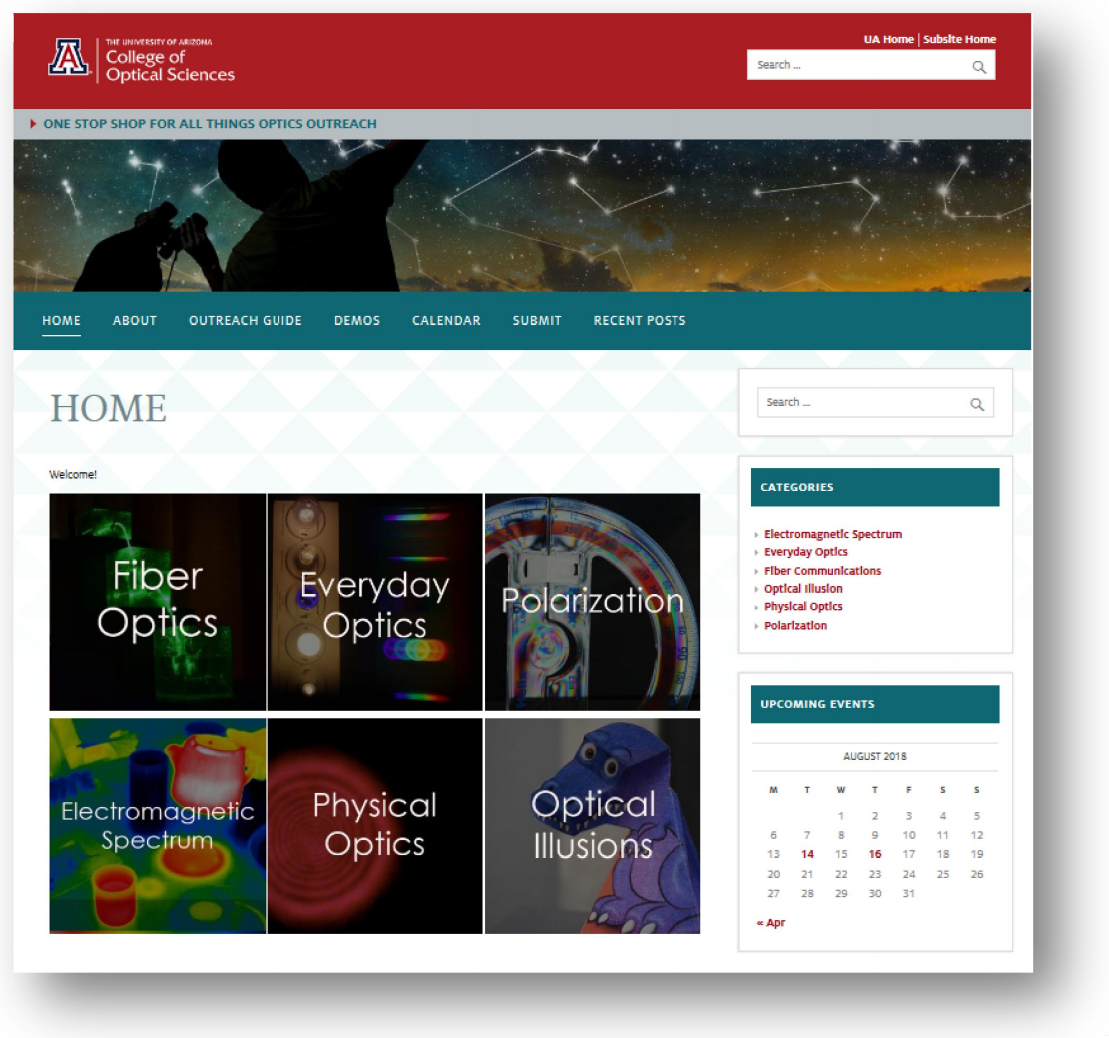

Figure 1. Demonstrations are grouped into categories, as shown in this screenshot of the online hub homepage ${ }^{8}$.

\subsection{Advantages}

Ongoing outreach events are utilized during the academic year to "beta-test" the website and improve the effectiveness of each lesson plan. Documenting all of the demonstrations available to students will encourage more efficient use of materials and add variety to the topics brought to the public most often. In addition, the website will be sustainable; lesson plans can be edited and added by SOCk, WiO, and CIAN, even with individual students cycling through OSC through the years.

While an online hub greatly enhances the many outreach activities already available to OSC students, online resources have the added benefit of being an accessible resource to teachers, students, and communities around the world. Though some demonstrations require specific equipment (such as an infrared camera), many activities can be modified and completed with simple household materials.

\section{RESULTS}

During the 2017 - 2018 Academic Year, OSC volunteers participated in 42 events, reaching over 6500 students in events across the Tucson community. Volunteers have utilized trial lesson plans in several classroom visits and community events, with full implementation of the hub to be completed in the coming year. 


\section{$2017-2018$ OSC Outreach}

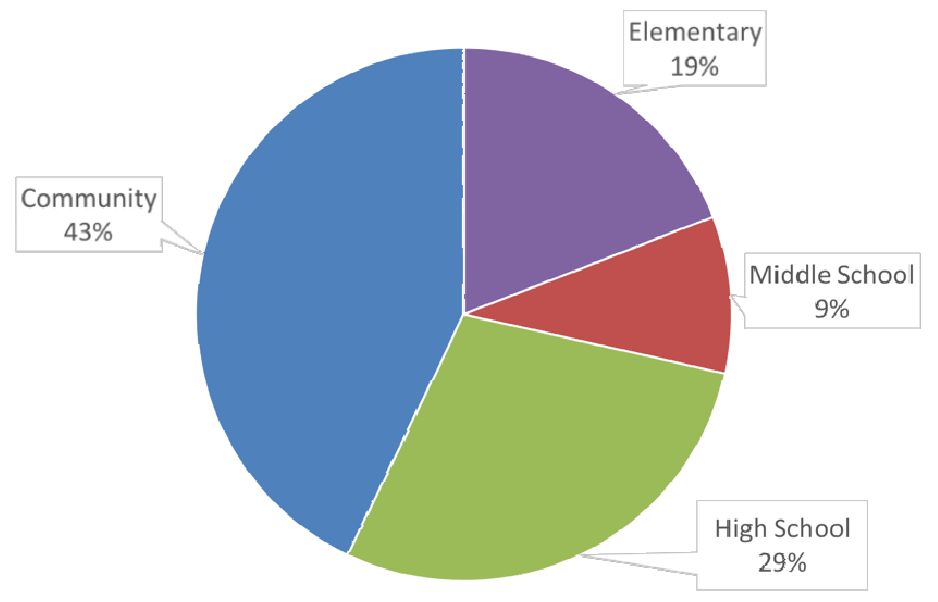

Figure 2. Throughout the 2017-2018 academic year, OSC volunteers participated in events for elementary, middle, and high school students, as well as community events which span all ages.

Available lesson plans describe some of the most popular OSC demonstrations such as Pepper's Ghost, polarization, diffraction of light sources, and Schlieren imaging, with images and videos as illustrated in Figure 3. Each demonstration will include step-by-step instructions, descriptions, and external resources as shown in Figure 4.
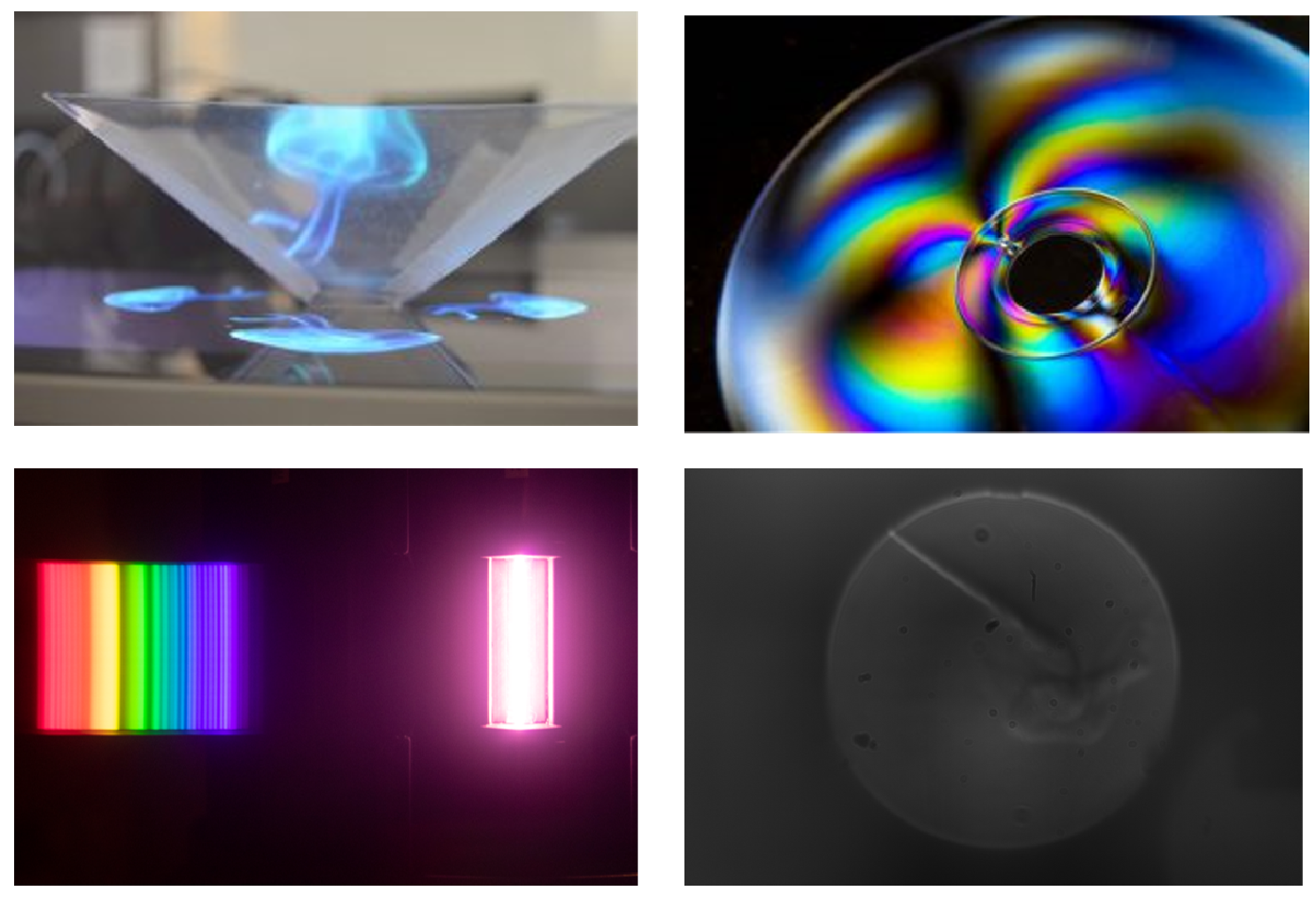

Figure 3. Example lesson plans include Pepper's Ghost, polarization, diffraction of light sources, and Schlieren imaging ${ }^{8}$. 


\section{PEPPER'S GHOST}

| April 18, 2018 | Emily Lesves comment | Edit Post

Overvlew: Pepper's Ghost was popularized in the 1800 s and continues to be used today in the entertainment industry, amusement parks, and museums. Aside from being an optical illusion, the technique is also the basis for how teleprompters work.

Tlme Requlred: 30 minutes

Ages: 8+

Supplles: Scissors, tape, transparent plastic (printable transparency sheets, CD cases, etc.).

Keywords: Reflection, optical illusion

Objectlves: What is Pepper's Ghost? How does light reflect off a surface? How do teleprompters work?

\section{Step-By-stap ingtructions:}

1) Print or trace the pattern below onto clear plastic (transparency sheet, $\mathrm{CD}$ cases, etc). Note: the pattern is scaled for a cell-phone screen or tablet.
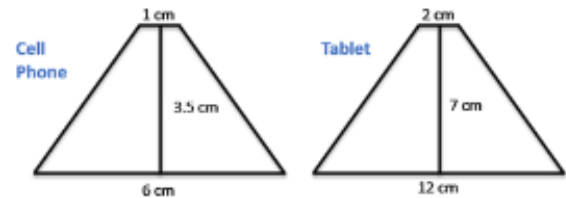

2) Cut out along the lines, and tape four trapezoids together as shown in the picture below.

3) Add the last piece of tape between the third and fourth trapezoid to form a pyramid.

4) $G 0$ to this Ilnk or google "Pepper's Pyramid Videos" to find a video that you like. The best videos will have a bright foreground and a black background.

5) Place the center of the pyramid on the center of your screen, turn down the room lights, turn up the brightness on your screen, and play the video.

6) When viewed edge-on, you will see a "floating" image:

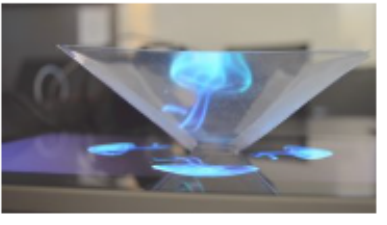

What's happening?

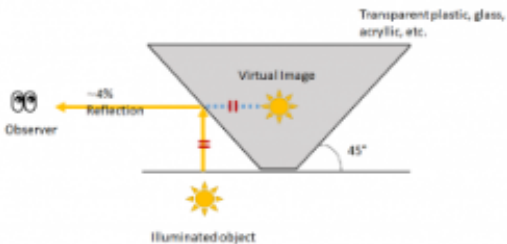

When light from a bright object (produced by the phone or tablet screen) reaches the transparent material, a portion of the light will reflect. For typical plastic, glas5, or acrylic, this will be about a $4 \%$ reflection. An observer looking at the side of the Pepper's Pyramid will then see a virtual image, an object that appears to float inside of the pyramid.

The reflection that you see is from one side of the pyramid. Having four sides allows the illusion to be seen from all angles, and seeing the other seams of the sides adds to the illusion that the floating image is contained by the pyramid.

Try this

- Lift up the pyramid off of the screen. Can you still see the image inside?

- Flip the pyramid upside down. What happens to the image?

Figure 4. Snippet of the Pepper's Ghost demonstration available on the online hub ${ }^{9}$. 


\section{FUTURE WORK}

An online infrastructure has been developed to create a sustainable resource for OSC outreach efforts, and additional work will be done to continue to grow this resource. Over the coming 2018-2019 academic year, the following steps will be taken:

1. Complete documentation of demonstrations and equipment available to OSC students;

2. Train representatives of the Student Optics Chapter (SOCk), Women in Optics (WiO), and the Center for Integrated Access Networks (CIAN) to utilize and edit the online hub;

3. Gather comments via the online hub to iteratively improve the lesson plans.

New demonstrations developed by undergraduate and graduate students in the Optics Outreach course (OPTI 489/589) will also be integrated into the online hub over the coming years.

\section{ACKNOWLEDGEMENTS}

This work was supported through a NASA traineeship grant awarded to the Arizona/NASA Space Grant Consortium. The authors would also like to acknowledge the support of the College of Optical Sciences for further development of outreach activities, as well as the volunteers of SOCk, WiO, and CIAN for their participation in outreach events throughout the academic year.

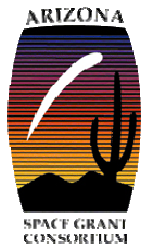

\section{REFERENCES}

[1] Nofziger, M., "Optics outreach from 8-12 microns: Wolfe-inspired," Proc. SPIE 8483, 848306 (2012).

[2] Nofziger, M., "Optics curriculum for middle school students," Proc. SPIE 2525, 213-224 (1995)

[3] Nofziger, M., "Talking over a beam of light: electro-optics suitable for K-12," Proc. SPIE 2525, 252-259 (1995).

[4] Cromey, B., Garret, Z., Noyes, M., and Bankhead, J., "2016 SPIE Student Chapter Report," https://spie.org/StudentChapterReports/UArizona_Report_201612.pdf.

[5] Cromey, B., "Laser Fun Day Report," https://blog.cian-erc.org/2014/06/24/laser-fun-day-report/.

[6] Ecklund, E.H., James, S.A., Lincoln, A.E., "How Academic Biologists and Physicists View Science Outreach," PLoS One, 22590526 (2012).

[7] "UA Graduate Fellowship Program," https://spacegrant.arizona.edu/students/fellowships.

[8] “One Stop Shop for All Things Optics Outreach,” https://wp.optics.arizona.edu/oscoutreach.

[9] “Pepper’s Ghost," https://wp.optics.arizona.edu/oscoutreach/2018/04/18/peppers-ghost/. 